Journal of Acute Disease

journal homepage: www.jadweb.org

\title{
Thyroid storm precipitated by acute biliary pancreatitis
}

\author{
Mehrdad Karimi $^{1}$, Adnan Tizmaghz ${ }^{2 *}$ \\ ${ }^{I}$ Minimally Invasive Surgery Research Center, Iran University of Medical Sciences, Tehran, Iran \\ ${ }^{2}$ Rasool-e-Akram Hospital, Iran University of Medical Sciences, Tehran, Iran
}

\section{ARTICLE INFO}

Article history:

Received 8 Sep 2016

Received in revised form 12 Oct 2016

Accepted 30 Oct 2016

Available online 8 Dec 2016

Keywords:

Thyroid storm

Biliary pancreatitis

Intra-abdominal infections

Thyroid hormone

\begin{abstract}
Thyroid storm is an acute, life-threatening exacerbation and sudden releasing large amounts of thyroid hormone in a short period of time. Nevertheless, critical aggravation of hyperthyroidism typically resulted from concurrent disorder. Synchronous management of thyroid storm along with its precipitant, such as infection is recommended. We described the case of an acute biliary pancreatitis complicated with a thyroid storm. The patient was successfully managed with a quick surgical intervention and further critical care for thyroid storm. Although it is widely believed that pancreatitis is seldom concurrent with thyrotoxicosis, thyroid storm can be precipitated by a variety of factors, including intra-abdominal infections such as acute pancreatitis or perforated peptic ulcer. In conclusion, acute pancreatitis in patients with thyrotoxicosis seems to be extremely rare, but such patients should be managed intensively against underlying thyroid disorders as well as pancreatitis.
\end{abstract}

\section{Introduction}

Thyroid storm or thyroid crisis is an acute, life-threatening exacerbation and sudden releasing large amounts of thyroid hormone in a short period of time. Only $1 \%-2 \%$ of people with hyperthyroidism will develop thyroid storm[1].

Thyroidectomy was formerly the most common cause of thyroid crisis. Nowadays post thyroidectomy crisis is an uncommon incidence, because of preoperative testing and earlier diagnosis and management. Nevertheless, critical aggravation of hyperthyroidism typically resulted from concurrent disorder, particularly infectious diseases and traumatic stress such as operation, still occur[2]. Thyroid crisis is especially related with Graves' disease (toxic diffuse goiter). However, it can also be present in toxic nodular goiter[3,4]. The classic symptoms of thyroid storm are greatly increased body temperature, and mental disturbance, accompanied by thyrotoxicosis symptoms $[5,6]$.

Here we describe the case of a patient with thyroid storm and an acute biliary pancreatitis. We also talk about the value of the identification of a pancreatitis in patients with thyroid storm.

\section{Case report}

A 35-year-old female was admitted to our hospital because

*Corresponding author: Adnan Tizmaghz, Rasool-e-Akram Hospital, Iran University of Medical Sciences, Tehran, Iran.

Tel: +982164352215

E-mail: karimi.mehrdad89@yahoo.com (M Karimi); adnan_ti@yahoo.com (A Tizmaghz)

The journal implements double-blind peer review practiced by specially invited international editorial board members. of nausea, vomiting and severe abdominal pain that developed suddenly. She had undergone laparoscopic mini-gastric bypass 18 months earlier. She has been taking daily multivitamin and vitamin B12 after her weight loss surgery. She had lost $54.5 \mathrm{~kg}$ or $75 \%$ of her excess body weight during these 18 months. She had never developed peptic ulcer disease before. She dose not smoke and has no history of hypertension, diabetes mellitus and thyroid disease.

At the time of admission to our hospital, she was febrile $\left(38.3{ }^{\circ} \mathrm{C}\right)$ with mild tachycardia (117 per minute) and normotensive (115/65 $\mathrm{mmHg}$ ). There was abdominal distention and marked generalized abdominal tenderness. Large quantities of free intraperitoneal fluid were detected on sonogram and it was otherwise normal. Laboratory investigations showed a white cell count of $12.2 \times$ $10^{3} / \mathrm{L}$, with $90 \%$ neutrophils, $14.3 \mathrm{IU} / \mathrm{L}$ total bilirubin, $6.4 \mathrm{IU} / \mathrm{L}$ direct bilirubin, $47 \mathrm{IU} / \mathrm{L}$ alanine transaminase, $58 \mathrm{IU} / \mathrm{L}$ aspartate transaminase, $273 \mathrm{IU} / \mathrm{L}$ alkaline phosphatase, $557 \mathrm{IU} / \mathrm{L}$ amylase, and $254 \mathrm{IU} / \mathrm{L}$ lactate dehydrogenase, and serum glucose was 240 $\mathrm{mg} / \mathrm{dL}$. The patient underwent diagnostic laparoscopy to evaluate a suspected acute intraabdominal process, and there was massive bile ascites, severely inflamed pancreas and gallbladder. Duodenum and previous gastrojejunostomy anastomosis were intact and patent. Intraoperatively, posterior wall gallbladder perforation was confirmed. Cholecystectomy was performed and a drain tube was placed to prevent accumulation of fluid at the surgical site and procedure was finished.

The results of presented thyroid profile test revealed a thyrotoxic crisis (free triiodothyronine $16.0 \mathrm{pg} / \mathrm{mL}$, free thyroxine $5.5 \mathrm{ng} / \mathrm{dL}$, and thyroid stimulating hormone $(\mathrm{TSH})<0.001 \mu \mathrm{IU} / \mathrm{mL}$ ).

The patient's condition suggested thyroid storm triggered by 
biliary pancreatitis considering his clinical signs and symptoms. We had not been able to determine the thyroid function preoperatively, because our laboratory did not measure thyroid hormone in the evening. Furthermore, we had not considered thyroid problems due to negative past medical history.

The patient was successfully treated with methimazole and propranolol. These medications were subsequently discontinued as her TSH and thyroid hormone levels were normalized. The patient was discharged after uneventful recovery period on the sixth day of surgery.

\section{Discussion}

Acute biliary pancreatitis is a serious complication of biliary calculous disease and is associated with significant morbidity and mortality[7]

Gallstones are the commonest cause of pancreatitis in the industrialized nations responsible for approximately $60 \%$ of the patients[8].

Sensitivity and specificity of ultrasound in the diagnosis of gallstones are about $95 \%$ in straightforward patients. However, sensitivity and specificity decreased to $67 \%-78 \%$ in the course of acute pancreatitis because of the paralytic ileus[9].

Pancreatitis can lead to serious problems including local complications (e.g. necrosis, pseudocyst, abscesses, bleeding) and systemic disease (e.g. accumulation of fluid in the pleura, acute respiratory distress syndrome, renal failure)[10].

Endoscopic retrograde cholangiopancreatography and sphincterotomy in patients with severe acute biliary pancreatitis must be considered within $72 \mathrm{~h}$. In mild acute biliary pancreatitis, all suitable cases must undergo laparoscopic gallbladder excision with intraoperative cholangiography, or if not suitable for gallbladder excision then endoscopic sphincterotomy can be considered to stop next biliary pancreatitis[11].

Perera et al. in 2013 reported a 39-year-old female presenting with concurrent acute cholecystitis and pancreatitis complicated by gall bladder perforation[12].

Page et al. in 2008 reported an 18-year-old male presenting with thyroid storm developed immediately after excision of a pituitary TSH-omas[13].

In the English literature, there are two reports of a patient with thyroid storm complicated with perforated peptic ulcer disease in 2006 and 2008[14]. These patients were treated successfully with rigorous medical therapy against hyperthyroidism and with surgical closure of the perforated peptic ulcer.

The severe weight loss caused by bariatric procedure induces specific middle or long term complications such as biliary lithiasis[15]. Thus, our patient had this risk factor for biliary stone formation. Although preoperative ultrasound had not shown any stone in gall bladder. Probably, it was due to a smaller stone which was passed down the common bile duct and the papilla resulting in temporarily obstruction of the pancreatic duct and acute pancreatitis.

Although our patient was not giving any history of thyroid disease, presentation of thyroid storm can be similar to acute abdomen, such as nausea, vomiting and severe abdominal pain[16]. Thus, preoperative thyroid hormonal evaluation and treatment of hormonal abnormalities in all clinically suspicious patients presenting with acute intra-abdominal process are important.

In conclusion, acute pancreatitis in patients with thyrotoxicosis seems to be extremely rare, but such patients should be managed intensively against underlying thyroid disorders as well as pancreatitis.

\section{Conflict of interest statement}

The authors report no conflict of interest.

\section{References}

[1] Schraga ED. Hyperthyroidism, thyroid storm, and Graves' disease. New York: Medscape; 2016 [Online] Available from: http://emedicine. medscape.com/article/767130 [Accessed on 2rd September, 2016]

[2] Swerdloff RS, Ng JCM. Gynecomastia: Etiology, Diagnosis, and Treatment. In: De Groot LJ, Chrousos G, Dungan K, Feingold KR, Grossman A, Hershman JM, et al. editors. Massachusetts, USA: MDText.com, Inc.

[3] Klubo-Gwiezdzinska J, Wartofsky L. Thyroid emergencies. Med Clin North Am 2012; 96: 385-403.

[4] Carroll R, Matfin G. Endocrine and metabolic emergencies: thyroid storm. Ther Adv Endocrinol Metab 2010; 1: 139-45.

[5] Leow MK, Chew DE, Zhu M, Soon PC. Thyrotoxicosis and acute abdomen-still as defying and misunderstood today? Brief observations over the recent decade. QJM 2008; 101(12): 943-7.

[6] Natsuda S, Nakashima Y, Horie I, Ando T, Kawakami A. Thyroid storm precipitated by duodenal ulcer perforation. Case Rep Endocrinol 2015; 2015: 750390 .

[7] Schepers NJ, van Santvoort HC, Bruno MJ, Dutch Pancreatitis Study Group. ERCP for gallstone pancreatitis. N Engl J Med 2014; 370: 1955.

[8] Mitchell RM, Byrne MF, Baillie J. Pancreatitis. Lancet 2003; 361: 1447-55.

[9] Manandhar S, Giri S, Poudel P, Bhandari RS, Lakhey PJ, Vaidya P. Acute biliary pancreatitis: an experience in a tertiary level hospital of Nepal. Indian J Surg 2013; 75(6): 449-53.

[10] McFadden DW. Organ failure and multiple organ system failure in pancreatitis. Pancreas 1991; 6(Suppl 1): S37-43.

[11] Working Party of the British Society of Gastroenterology; Association of Surgeons of Great Britain and Ireland; Pancreatic Society of Great Britain and Ireland; Association of Upper GI Surgeons of Great Britain and Irelan. UK guidelines for the management of acute pancreatitis. Gut 2005; 54(Suppl 3): iii1-9.

[12] Perera M, Pham T, Toshniwal S, Lennie Y, Chan S, Houli N. A case of concomitant perforated acute cholecystitis and pancreatitis. Case Rep Surg 2013; 2013: 263046.

[13] Page KA, Roehmholdt BF, Jablonski M, Mayerson AB. Development of thyroid storm after surgical resection of a thyrotropin-secreting pituitary adenoma. Endocr Pract 2008; 14(6): 732-7.

[14] Ogiso S, Inamoto S, Hata H, Yamaguchi T, Otani T, Koizumi K. Successful treatment of gastric perforation with thyrotoxic crisis. Am J Emerg Med 2008; 26(9): 1065.

[15] Veyrie N, Servajean S, Berger N, Loire P, Basdevant A, Bouillot JL. [Gallbladder complications after bariatric surgery]. Gastroenterol Clin Biol 2007; 31(4): 378-84. Frence.

[16] Matar ZS. Thyroid storm presenting as acute abdomen and normothermia. J Family Community Med 2004; 11(3): 115-7. 